\title{
High concentrations of glucose reduce the oxidative metabolism of dog neutrophils in vitro
}

\author{
Anelise M Bosco ${ }^{*}$, Breno FM de Almeida, Priscila P Pereira, Luis G Narciso, Valéria MF Lima and Paulo C Ciarlini
}

\begin{abstract}
Background: Dogs are commonly affected by hyperglycemic conditions. Hyperglycemia compromises the immune response and favors bacterial infections; however, reports on the effects of glucose on neutrophil oxidative metabolism and apoptosis are conflicting in humans and rare in dogs. Considering the many complex factors that affect neutrophil oxidative metabolism in vivo, we investigated in vitro the specific effect of high concentrations of glucose on superoxide production and apoptosis rate in neutrophils from healthy dogs.

Results: The capacity of the neutrophils to reduce tetrazolium nitroblue decreased significantly in the higher concentration of glucose $(15.13 \pm 9.73 \%(8 \mathrm{mmol} / \mathrm{L})$ versus $8.93 \pm 5.71 \%(16 \mathrm{mmol} / \mathrm{L}))$. However, there were no changes in tetrazolium nitroblue reduction at different glucose concentrations when the neutrophils were first activated with phorbol myristate acetate. High concentrations of glucose did not affect the viability and apoptosis rate of canine neutrophils either with or without prior camptothecin stimulation. This study provides the first evidence that high concentrations of glucose inhibit the oxidative metabolism of canine neutrophils in vitro in a manner similar to that which occurs in humans, and that the decrease in superoxide production did not increase the apoptosis rate.

Conclusions: A high concentration of glucose reduces the oxidative metabolism of canine neutrophils in vitro. It is likely that glucose at high concentrations rapidly affects membrane receptors responsible for the activation of NADPH oxidase in neutrophils; therefore, the nonspecific immune response can be compromised in dogs with acute and chronic hyperglycemic conditions.
\end{abstract}

Keywords: Superoxide, Respiratory burst, Programmed cell death, Leukocyte dysfunction, Hyperglycemia

\section{Background}

Hyperglycemia occurs frequently in critically ill dogs hospitalized in intensive care units (16\%), and their morbidity is directly associated with their blood glucose concentration [1]. In humans, functional defects in neutrophils that diminish the microbicidal and phagocytic function of the cells and increase the risk of bacterial infection are attributed to hyperglycemia [2]. The molecular, biochemical and cellular basis of this decrease in immunological defense is not well understood in humans [3], and the relationship between hyperglycemia and neutrophil dysfunction in dogs remains to be adequately investigated.

\footnotetext{
* Correspondence: anebosco@hotmail.com

Department of Clinical, Surgery and Animal Reproduction, College of Veterinary Medicine of Araçatuba, São Paulo State University, Araçatuba, SP, Brazil
}

\section{Ciomed Central}

Reactive oxygen species (ROS), including superoxide anion and its derivatives, exert an important bactericidal function in neutrophils and are components of some of the conditions associated with the pathogenesis of diabetes [4]. However, the effect of hyperglycemia on neutrophil production of ROS is unclear. Some studies have reported increased ROS production in diabetic patients [5,6,7], and in healthy patients that underwent a hyperglycemic challenge [8]. The reduction of the neutrophil oxidative burst in patients with poorly controlled diabetes mellitus has also been described [9], but such alteration did not occur in patients with experimentally varied concentrations of blood glucose [10] and with acute, induced hyperglycemia [11].

There are many complex factors affecting the neutrophil respiratory burst in vivo, and different concentrations of blood glucose in patients can also affect the oxidative metabolism of neutrophils. Thus, to minimize 
these factors, in vitro protocols have been used to provide an adequate understanding of how glucose concentrations can affect the oxidative metabolism of neutrophils. Neutrophils from healthy individuals, when incubated with high concentrations of glucose in vitro, have lower superoxide anion production $[12,2,13]$. In humans, the in vitro inhibition of neutrophil oxidative metabolism seems to be dependent on glucose concentration. Perner et al. [14] incubated neutrophils from healthy patients in solutions containing $5 \mathrm{mmol} / \mathrm{L}, 10 \mathrm{mmol} / \mathrm{L}$ and $25 \mathrm{mmol} / \mathrm{L}$ of glucose and verified $50 \%$ inhibition of superoxide production in the highest glucose concentration.

Nielson et al. [12] suggest that the suppressing effect of glucose on the oxidative metabolism of neutrophils is due to protein glycosylation. Monosaccharides such as glucose, mannose and fructose form Schiff-base adducts with proteins, which cause inhibition of neutrophil function. Four mechanisms underlie the oxidative stress associated with hyperglycemia: increased polyol pathway flux, increased advanced glycation end product (AGE) formation, activation of protein kinase $\mathrm{C}$ (PKC) isoforms, and increased hexosamine pathway flux [15].

There is evidence that oxidative stress in diabetics increases apoptosis of neurons [16], endothelial cells [17], pancreatic cells [18], mesangial cells [19], and renal podocytes [20]. However, the relationship between hyperglycemia and neutrophil viability needs further study. According to Tennenberg et al. [21], high concentrations of blood glucose decrease the functional longevity of human neutrophils and increase neutrophil clearance from infected sites, possibly contributing to the increased susceptibility to and severity of infections in diabetic patients. In contrast, Turina et al. [22] observed no alteration in human neutrophil apoptosis when exposed to high concentrations of plasma glucose. In diabetic rats, the glycolytic metabolism and the protector effect of glutamine on neutrophils is altered, accelerating apoptosis and increasing susceptibility to infections [23].

Although dogs are commonly affected by diabetic hyperglycemia and are considered the best animal model for the study of human diabetes [23], there are few studies examining the effect of glucose on neutrophil oxidative metabolism and apoptosis in dogs. The decrease in $\mathrm{NADPH}$ oxidase activity seen in the neutrophils of dogs fed high levels of galactose results from excessive consumption of enzyme due to increased polyol pathway activity [24]. In this circumstance, excessive consumption of NADPH decreases superoxide production and compromises the bactericidal function of neutrophils. A diabetic retinopathy, similar to that which occurs in humans, was induced in dogs fed a $30 \%$ galactose diet. When isolated neutrophils from healthy dogs were incubated with a similar concentration of galactose there was no alteration in their apoptosis rate; however, in vivo evaluation of neutrophils revealed a lower apoptosis rate and higher adhesion in galactose-fed dogs [25].

In vitro studies are necessary to evaluate the specific effects of glucose on neutrophil oxidative metabolism and apoptosis, especially in diabetic dogs and hyperglycemic conditions. The aim of this study was to test, in vitro, whether high concentrations of glucose inhibit the oxidative metabolism of isolated neutrophils from healthy dogs, and also to evaluate the viability and apoptosis rate of these cells when incubated in different concentrations of glucose.

\section{Results}

\section{A high glucose concentration inhibits the oxidative metabolism of canine neutrophils}

The interference of glucose with the oxidative metabolism of human neutrophils has been described [2,12,14]. This interference was evaluated in dogs using the NBT reduction test to quantify the superoxide production of neutrophils from healthy dogs in RPMI medium containing a high concentration of glucose.

Neutrophils incubated in pure RPMI medium reduced significantly more NBT than neutrophils incubated in RPMI with a high concentration of glucose (15.13 \pm $9.73 \%(8 \mathrm{mmol} / \mathrm{L})$ versus $8.93 \pm 5.71 \%(16 \mathrm{mmol} / \mathrm{L}))$. Thus, similar to the effects seen in human neutrophils in vitro [14], superoxide production decreased in canine neutrophils in the presence of a high concentration of glucose. However, no inhibitory effects on neutrophil oxidative metabolism were observed when the cells had been previously activated with PMA (Table 1).

\section{Maintenance of neutrophil viability during incubation with a high concentration of glucose}

We compared the viability and apoptosis rate of neutrophils isolated from healthy dogs and incubated in pure RPMI media or in RPMI media with addition of glucose. The protocol for neutrophil isolation and incubation in RPMI media did not compromise cell viability, even though the glucose concentration of RPMI media is $8 \mathrm{mmol} / \mathrm{L}$, which is higher than that of normal dog plasma (4-6 mmol/L) (Table 2). When apoptosis was stimulated with CAM, there was a decrease in viability associated with increased neutrophil apoptosis in both the pure and the glucose-enriched media. RPMI enriched with glucose resulted in a numerical increase in the apoptosis rate; however, this difference was not statistically significant.

\section{Discussion}

Multiple cellular factors have been associated with neutrophil dysfunction in hyperglycemic conditions. These include nicotinamide [9], protein components of 
Table 1 Oxidative metabolism of neutrophils from healthy dogs at two different concentrations of glucose

\begin{tabular}{ccc}
\hline \multirow{2}{*}{$\begin{array}{c}\text { Glucose } \\
\text { concentration }\end{array}$} & \multicolumn{2}{c}{ Percentage of neutrophils reducing NBT } \\
\cline { 2 - 3 } & Spontaneous & PMA activation \\
\hline $\mathbf{8} \mathbf{~ m m o l} / \mathbf{L}$ & $15.13 \pm 9.73^{\mathrm{a}}$ & $73.66 \pm 8.52^{\mathrm{a}}$ \\
$\mathbf{1 6} \mathbf{~} \mathbf{m o l} / \mathbf{L}$ & $8.93 \pm 5.71^{\mathrm{b}}$ & $72.20 \pm 9.71^{\mathrm{a}}$ \\
$\mathbf{p}$-value & 0.0304 & 0.6444 \\
\hline
\end{tabular}

* Different letters in the same column indicate a statistically significant difference.

NADPH oxidase [26], intracytoplasmic cytokines [27], chemokines [28], expression of pro-inflammatory genes [11], and alterations in several different mechanisms of cellular activation as well as modifications of proteins and lipids [29]. However, the complete mechanism underlying glucose-associated neutrophil dysfunction is still unknown.

In this study, we verified in vitro that neutrophils of healthy dogs decrease superoxide production when incubated in a high concentration of glucose $(16 \mathrm{mmol} / \mathrm{L})$. Similar results were observed in human neutrophils incubated with elevated concentrations of glucose such as $\geq 11 \mathrm{mmol} / \mathrm{L}$ [12], $\geq 13.8 \mathrm{mmol} / \mathrm{L}$ [2] and $25 \mathrm{mmol} / \mathrm{L}$ [14]. These results reinforce the affirmation of Ionut et al. (2010) [30] that the dog is the most suitable model for the study of human diabetes.

The in vitro inhibitory effect of glucose on the oxidative metabolism of canine neutrophils has also been observed in humans in vivo [9]; however, some studies did not find alterations in the oxidative metabolism of diabetic patients $[10,11]$, while others found increased oxidative metabolism $[8,5,6,7]$. This discrepancy among the results of studies that evaluated neutrophil oxidative metabolism may be due to the heterogeneity of their protocols; different concentrations of glucose were used, various stimuli were used to activate the cells, and oxidative metabolism was assessed by different methods [3]. Although the NBT method is not able to determine the precise concentration of superoxide produced, in this study and in others $[31,32,33,34]$ it was possible to assess neutrophil oxidative metabolism using this method.

Neutrophil activation occurs by a variety of distinct mechanisms of signal transduction. Some neutrophil activators depend on complement (calcium ionophore A23187), while others require opsonization (zymosan) and others, such as N-formyl-methionine-leucinephenylalanine (fMLP), depend on specific protein receptors [35]. In this study, the potent neutrophil activator PMA was used. PMA does not require receptors to activate NADPH oxidase, instead inducing superoxide production directly by protein kinase $\mathrm{C}$ activation [36]. According to Mcmanus et al. (2001) [3], in diabetic patients neutrophil activation occurs only in the presence of stimuli that initiate signal transduction via G-protein coupled receptors, thus it does not occur in the presence of PMA. This may explain why excessive glucose in the media did not alter the oxidative metabolism of neutrophils activated with PMA, and suggests that the inhibition of oxidative metabolism observed in the trials without PMA is due to a failure in G-protein coupled signal transduction, which is responsible for NADPH oxidase activation.

There is evidence that a high concentration of glucose decreases neutrophil functional longevity in humans and increases neutrophil clearance from infected sites, possibly contributing to the increased susceptibility to and severity of infections in diabetic patients [21]. The mechanisms related to the acceleration of apoptosis during hyperglycemia are associated with decreased resistance to oxidative stress, increases in protein glycosylation, and decreased protective effect of glutamine [23].

Oxidative stress associated with short-term hyperglycemia increases the apoptosis rate of neurons [16] and renal podocytes [20]. Conversely in our study, neutrophils maintained for a short period $(4 \mathrm{~h})$ in glucose-rich media did not have an increased apoptosis rate. Similar results were observed in human neutrophils incubated for $24 \mathrm{~h}$ with high $(100 \mathrm{mg} / \mathrm{dL})$ and low $(10 \mathrm{mg} / \mathrm{dL})$ concentrations of glucose [22]. Similarly, no acceleration of neutrophil apoptosis was observed in diabetes-induced dogs [25] and rats [37]. Therefore, it is reasonable to assume that the varying results regarding the assessment of neutrophil apoptosis in short-period experiments are due to a proapoptotic effect of glucose that only occurs in conditions of persistent hyperglycemia.

Table 2 Viability and apoptosis of neutrophils from healthy dogs incubated at two glucose concentrations

\begin{tabular}{|c|c|c|c|c|c|c|c|c|}
\hline \multirow{3}{*}{$\begin{array}{c}\text { Glucose } \\
\text { concentration }\end{array}$} & \multicolumn{8}{|c|}{ Percentage of neutrophils } \\
\hline & \multicolumn{4}{|c|}{ Spontaneous } & \multicolumn{4}{|c|}{ CAM activation } \\
\hline & Viability & $\begin{array}{c}\text { Initial } \\
\text { apoptosis }\end{array}$ & $\begin{array}{c}\text { Final } \\
\text { apoptosis }\end{array}$ & $\begin{array}{c}\text { Total } \\
\text { apoptosis }\end{array}$ & Viability & $\begin{array}{c}\text { Initial } \\
\text { apoptosis }\end{array}$ & $\begin{array}{c}\text { Final } \\
\text { apoptosis }\end{array}$ & $\begin{array}{c}\text { Total } \\
\text { apoptosis }\end{array}$ \\
\hline $8 \mathrm{mmol} / \mathrm{L}$ & $97.93 \pm 2.44$ & $0.19 \pm 0.19$ & $0.19 \pm 0.12$ & $0.38 \pm 0.23$ & $69.91 \pm 15.34$ & $5.87 \pm 4.77$ & $19.16 \pm 13.09$ & $25.04 \pm 14.60$ \\
\hline $16 \mathrm{mmol} / \mathrm{L}$ & $97.76 \pm 1.90$ & $0.22 \pm 0.23$ & $0.26 \pm 0.24$ & $0.49 \pm 0.43$ & $67.73 \pm 12.31$ & $6.54 \pm 5.72$ & $22.21 \pm 15.04$ & $28.76 \pm 12.66$ \\
\hline$p$-value & 0.8221 & 0.6812 & 0.4202 & 0.3593 & 0.6508 & 0.7132 & 0.5327 & 0.4332 \\
\hline
\end{tabular}




\section{Conclusions}

This study provides the first evidence that high concentrations of glucose inhibit the oxidative metabolism of canine neutrophils in vitro, and that this inhibition does not alter the apoptosis rate and viability of the neutrophils. High concentrations of glucose may rapidly affect the membrane receptors responsible for the activation of NADPH oxidase; in this way even short-term hyperglycemia can compromise the oxidative metabolism of canine neutrophils. However, further investigations are required to evaluate the clinical implications of these results.

\section{Methods}

\section{Animal selection}

Seventeen adult mongrel dogs of both sexes were used. Only dogs with no abnormalities on physical examination and laboratory tests (hemogram, plasma fibrinogen, urinalysis, plasma albumin, urea, creatinine, uric acid, cholesterol, glucose, and fructosamine) were included. The region is endemic for leishmaniasis, and dogs were selected for the study only after negative serological testing. No animal that had recently received treatment with any drug was included in the experiment. The study was approved by the Animal Experimentation Ethics Committee of the Faculty of Veterinary Medicine of São Paulo State University and samples were obtained with the consent of the owners.

\section{Samples collection and maintenance}

Whole blood samples were collected using disposable needles and syringes and kept in heparinized sterile glass tubes with $10 \mathrm{U}$ of heparin (Vacutainer plus plastic Heparin, Cod. 367993, Becton-Dickson, New Jersey, USA) per $1 \mathrm{~mL}$ of whole blood. All the samples were protected from light and kept at $4^{\circ} \mathrm{C}$ for a maximum period of $2 \mathrm{~h}$ before analysis. Urine samples were collected by cystocentesis and were also kept at $4{ }^{\circ} \mathrm{C}$ and protected from light until analysis.

\section{Biochemical analyses, hemogram and urinalysis}

All biochemical tests were performed using commercial reagents (BioSystems Reagents, Barcelona, Spain) at $37^{\circ} \mathrm{C}$ in an automated analyzer (Automatic Analyzer BTS, Mod. 370 plus, BioSystems) that had been previously calibrated with a commercial calibrator, and reaction quality was monitored with control levels I and II (Biosystems, Barcelona, Spain). Plasma urea concentration was determined using the urease/glutamate dehydrogenase-coupled UV enzymatic assay, creatinine using the alkaline picrate kinetic assay, albumin using the bromocresol green assay, uric acid using the uricase/peroxidase enzymatic assay, cholesterol and glucose by the enzymatic oxidase/ peroxidase method, and fructosamine by the colorimetric method of NBT reduction.

White blood cell counts were performed in an automated veterinary blood cell counter (Veterinary hematological electronic cell counter, Mod. CC-530, CELM, São Paulo, Brazil). Differential white cell counts were accomplished using optical microscopy by the differentiation of 100 white cells in a blood smear stained with panoptic dye (InstantProv, Newprov, Pinhais-PR). Plasma fibrinogen was estimated indirectly by refractometry (Refratometre ATAGO ${ }^{\circledR}$ SPR-T2, ATAGO Co., LTD, Japan) using the heat precipitation method $\left(56-58^{\circ} \mathrm{C}\right)$.

Urinalysis was performed as described by Osborne et al. (1995) [38] using commercial reagent strips for chemical analysis (Combur 10 test $^{\circledR}$, Roche, Mannheim, Germany) and refractometry for density determination.

\section{Neutrophil isolation}

A double gradient separation technique was used to isolate neutrophils. Four $\mathrm{mL}$ of heparinized whole blood $(10 \mathrm{IU} / \mathrm{mL})$ were transferred to sterile polypropylene conical tubes containing equal volumes $(3 \mathrm{~mL})$ of Histopaque-1119 and 1077 (Sigma, St. Louis, MO, USA). Following centrifugation at $340 \mathrm{G}$ for $30 \mathrm{~min}$, the layer of polymorphonuclear (PMN) cells was aspirated and washed twice with aqueous ammonium chloride $(0.14 \mathrm{M})$ to ensure complete lysis of the residual erythrocytes. Next, the sample was centrifuged (100 G) for 5 min in Hanks' balanced salt solution (HBSS) (Sigma) without $\mathrm{Ca} 2+$ and $\mathrm{Mg} 2+$ and $1 \mathrm{~mL}$ of RPMI media (Sigma) was added to the cell sediment. Cell concentration was determined in a hemocytometer and cell viability was estimated by the blue trypan dye exclusion method. The sample of isolated PMNs was diluted in RPMI to obtain a final cell concentration of $10^{6} \mathrm{~mL}$, with the purity and viability of neutrophils equal to or more than 90 and $95 \%$, respectively.

\section{Determination of neutrophil superoxide production}

Neutrophil superoxide production was estimated by the nitroblue tetrazolium (NBT) reduction test. Briefly, $100 \mu \mathrm{L}$ of the neutrophil suspension $\left(10^{6} / \mathrm{mL}\right)$ was incubated in two sterile microtubes with $50 \mu \mathrm{L}$ of $0.2 \% \mathrm{NBT}$ solution in saline. For the stimulated test, $1 \mu \mathrm{L}(535 \mu \mathrm{mol} / \mathrm{L})$ of PMA (Phorbol 12-myristate 13-acetate, Cat. P8139, Sigma) was added. After incubation in a thermal shaker at $37^{\circ} \mathrm{C}$ for 10 $\mathrm{min}$, the samples were cytocentrifuged at $400 \mathrm{G}$ for $5 \mathrm{~min}$ and then stained with panoptic dye. The percentage of positive cells was assessed by counting 100 cells.

\section{Determining the viability and apoptotic index of the neutrophils}

The percentage of apoptotic cells and viable neutrophils was determined using the Annexin V-PE assay Kit 
(Guava Nexin Kit, Guava Technologies, USA). The procedure for each test and proper instrument performance were verified in accordance with the manufacturer's recommendations. Briefly, two samples of $100 \mu \mathrm{L}$ of neutrophils $\left(10^{6} / \mathrm{mL}\right)$ suspended in RPMI were incubated at $37^{\circ} \mathrm{C}$ for $1 \mathrm{~h}$ with $100 \mu \mathrm{L}$ of RPMI medium (CAM absent) and with $100 \mu \mathrm{L}$ of camptothecin $(19.8 \mathrm{mmol} / \mathrm{L}$, Sigma). Following incubation, $100 \mu \mathrm{L}$ of each sample was transferred to a microtube with $100 \mu \mathrm{L}$ of annexin V-PE reagent and incubated in the dark at room temperature for $10 \mathrm{~min}$. In a capillary flow cytometer EasyCyte mini ${ }^{\circledR}$ (Guava, Hayward, CA) 10,000 events were acquired, and viable, apoptotic populations of neutrophils were delineated using a specific computer program (Software Express Plus ${ }^{\circledR}$ Guava, Hayward, CA).

\section{In vitro experimental design to test the hypothesis that glucose alters the oxidative metabolism and apoptosis of neutrophils from healthy dogs}

Neutrophils were isolated from 17 healthy dogs and incubated in RPMI with two different concentrations of glucose ( 8 and $16 \mathrm{mmol} / \mathrm{L})$. After $2 \mathrm{~h}$ of incubation, the superoxide production and the apoptosis rate of the neutrophils were evaluated in spontaneous and stimulated trials as described above.

\section{Statistical analysis}

Statistical tests were performed after testing the distributions of the variables for normality (Kolmogorov-Smirnov test). Differences between control and hyperglycemic groups were assessed using paired t-tests, with $P$ values of $\leq 0.05$ considered significant. SAS software (SAS Institute Inc., The SAS System, release 9.2., Cary: NC, 2008) was used for all statistical analyses.

\section{Abbreviations}

AMB: Anelise Maria Bosco; BFMA: Breno Fernando Martins de Almeida; PPP: Priscila Preve Pereira; LGN: Luis Gustavo Narciso; VMFL: Váleria Marçal Felix de Lima; PCC: Paulo César Ciarlini.

\section{Competing interests}

The authors declare that they have no competing interests.

\begin{abstract}
Authors' contributions
AMB: Principal investigator, performed the experiment, analyzed the data, mainly wrote the paper; BFMA: analysis and interpretation of the data; PPP: analysis and interpretation of the data; LGN: conduction of the study, interpretation of the data; VMFL: substantial contribution to acquisition of the data for the flow citometry analysis; PCC: statistical analyses, interpretation of the data, supervised the study. All authors participated in the writing of the paper and have read and approved the final manuscript.
\end{abstract}

\section{Acknowledgements}

Foundation for Research Support of the State of São Paulo, or FAPESP.

Received: 3 August 2012 Accepted: 1 February 2013

Published: 6 February 2013

\section{References}

1. Torre DM, DeLaforcade AM, Chan DL: Incidence and clinical relevance of hyperglycemia in critically ill dogs. J Vet Intern Med 2007, 21(5):971-975.

2. Marhoffer W, Stein M, Schleinkofer L, Federlin K: Evidence of ex vivo and in vitro impaired neutrophil oxidative burst and phagocytic capacity in type 1 diabetes mellitus. Diabetes Res Clin Pract 1993, 19(3):183-188.

3. McManus LM, Bloodworth RC, Prihoda TJ, Blodgett JL, Pinckard RN: Agonistdependent failure of neutrophil function in diabetes correlates with extent of hyperglycemia. J Leukoc Biol 2001, 70(3):395-404.

4. Kawahito S, Kitahata H, Oshita S: Problems associated with glucose toxicity: role of hyperglycemia-induced oxidative stress. World J Gastroenterol 2009, 15(33):4137-4142.

5. Shetty N, Thomas B, Ramesh A: Comparison of neutrophil functions in diabetic and healthy subjects with chronic generalized periodontitis. $J$ Indian Soc Periodontol 2008, 12(2):41-44.

6. Omori K, Ohira T, Uchida Y, Ayilavarapu S, Batista EL, Yagi M, Iwata T, Liu H, Hasturk $\mathrm{H}$, Kantarci A, et al: Priming of neutrophil oxidative burst in diabetes requires preassembly of the NADPH oxidase. J Leukoc Biol 2008, 84(1):292-301

7. Pisarczyk-Wiza D, Zozulińska-Ziółkiewicz D, Wysocki H, Wierusz-Wysocka B: Increase in glycaemia stimulates reactive oxygen species (ROS) production by polymorphonuclear neutrophils in type 2 diabetic patients. Journal of Pre-Clinical and Clinical Research 2011, 5:22-27.

8. Mohanty P, Hamouda W, Garg R, Aljada A, Ghanim H, Dandona P: Glucose challenge stimulates reactive oxygen species (ROS) generation by leucocytes. J Clin Endocrinol Metab 2000, 85(8):2970-2973.

9. Osar Z, Samanci T, Demirel GY, Damci T, Ilkova H: Nicotinamide effects oxidative burst activity of neutrophils in patients with poorly controlled type 2 diabetes mellitus. Exp Diabesity Res 2004, 5(2):155-162.

10. Fejfarová V, Jirkovská A, Lupínková J, Kovár J, Kalanin J, Stríz I, Skibová J, Boucek P, Pelikánová T: Effect of acute hyperglycemia and/or hyperinsulinemia on polymorphonuclear functions in healthy subjects. Metabolism 2006, 55(6):811-818.

11. Stegenga ME, van der Crabben SN, Dessing MC, Pater JM, van den Pangaart PS, de Vos AF, Tanck MW, Roos D, Sauerwein HP, van der Poll T: Effect of acute hyperglycaemia and/or hyperinsulinaemia on proinflammatory gene expression, cytokine production and neutrophil function in humans. Diabet Med 2008, 25(2):157-164.

12. Nielson CP, Hindson DA: Inhibition of polymorphonuclear leukocyte respiratory burst by elevated glucose concentrations in vitro. Diabetes 1989, 38(8):1031-1035.

13. Cendoroglo M, Sundaram S, Jaber BL, Pereira BJ: Effect of glucose concentration, osmolality, and sterilization process of peritoneal dialysis fluids on cytokine production by peripheral blood mononuclear cells and polymorphonuclear cell functions in vitro. Am J Kidney Dis 1998 31(2):273-282

14. Perner A, Nielsen SE, Rask-Madsen J: High glucose impairs superoxide production from isolated blood neutrophils. Intensive Care Med 2003, 29(4):642-645.

15. Rolo AP, Palmeira CM: Diabetes and mitochondrial function: role of hyperglycemia and oxidative stress. Toxicol Appl Pharmacol 2006, 212(2):167-178.

16. Vincent AM, McLean LL, Backus C, Feldman EL: Short-term hyperglycemia produces oxidative damage and apoptosis in neurons. FASEB J 2005, 19(6):638-640

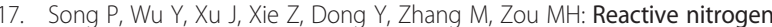
species induced by hyperglycemia suppresses Akt signaling and triggers apoptosis by upregulating phosphatase PTEN (phosphatase and tensin homologue deleted on chromosome 10) in an LKB1-dependent manner. Circulation 2007, 116(14):1585-1595.

18. Song F, Jia W, Yao Y, Hu Y, Lei L, Lin J, Sun X, Liu L: Oxidative stress, antioxidant status and DNA damage in patients with impaired glucose regulation and newly diagnosed Type 2 diabetes. Clin Sci (Lond) 2007, 112(12):599-606.

19. Kang BP, Frencher S, Reddy V, Kessler A, Malhotra A, Meggs LG: High glucose promotes mesangial cell apoptosis by oxidant-dependent mechanism. Am J Physiol Renal Physiol 2003, 284(3):F455-466.

20. Susztak K, Raff AC, Schiffer M, Böttinger EP: Glucose-induced reactive oxygen species cause apoptosis of podocytes and podocyte depletion at the onset of diabetic nephropathy. Diabetes 2006, 55(1):225-233. 
21. Tennenberg SD, Finkenauer R, Dwivedi A: Absence of lipopolysaccharideinduced inhibition of neutrophil apoptosis in patients with diabetes. Arch Surg 1999, 134(11):1229-1233. discussion 1233-1224.

22. Turina M, Miller FN, Tucker C, Polk HC: Effects of hyperglycemia, hyperinsulinemia, and hyperosmolarity on neutrophil apoptosis. Surg Infect (Larchmt) 2006, 7(2):111-121.

23. Alba-Loureiro TC, Hirabara SM, Mendonça JR, Curi R, Pithon-Curi TC: Diabetes causes marked changes in function and metabolism of rat neutrophils. J Endocrinol 2006, 188(2):295-303.

24. Fukase S, Sato S, Mori K, Secchi EF, Kador PF: Polyol pathway and NADPHdependent reductases in dog leukocytes. J Diabetes Complications 1996, 10(6):304-313.

25. Ohta N, Tsai JY, Secchi EF, Kador PF, Sato S: Neutrophils in galactose-fed dogs: suppressed apoptosis and increased adhesion to retinal capillary endothelial cells. J Diabetes Complications 1999, 13(3):151-158.

26. Quinn MT, Gauss KA: Structure and regulation of the neutrophil respiratory burst oxidase: comparison with nonphagocyte oxidases. J Leukoc Biol 2004, 76(4):760-781.

27. Bilgic S, Aktas E, Salman F, Ersahin G, Erten G, Yilmaz MT, Deniz G. Intracytoplasmic cytokine levels and neutrophil functions in early clinical stage of type 1 diabetes. Diabetes Res Clin Pract 2008, 79(1):31-36.

28. Graves DT, Naguib G, Lu H, Leone C, Hsue H, Krall E: Inflammation is more persistent in type 1 diabetic mice. J Dent Res 2005, 84(4):324-328.

29. Niedowicz DM, Daleke DL: The role of oxidative stress in diabetic complications. Cell Biochem Biophys 2005, 43(2):289-330.

30. Ionut V, Liu H, Mooradian V, Castro AV, Kabir M, Stefanovski D, Zheng D, Kirkman EL, Bergman RN: Novel canine models of obese prediabetes and mild type 2 diabetes. Am J Physiol Endocrinol Metab 2010, 298(1):E38-48.

31. Gómez-Ochoa P, Lara A, Couto G, Marcen JM, Peris A, Gascón M, Castillo JA: The nitroblue tetrazolium reduction test in canine leishmaniasis. Vet Parasitol 2010, 172(1-2):135-138.

32. Gómez-Ochoa P, Sabate D, Homedes J, Ferrer L: Use of the nitroblue tetrazolium reduction test for the evaluation of Domperidone effects on the neutrophilic function of healthy dogs. Vet Immunol Immunopathol 2012, 146:97-99.

33. Emanuelli MP, Martins DB, Wolkmer P, Antoniazzi AQ: Emanuelli T, de Vargas AC, dos Anjos Lopes ST: Complete blood count, total plasma protein, neutrophil oxidative metabolism, and lipid peroxidation in female dogs with pyometra associated with Escherichia coli. Comp Clin Pathol 2012, 21:309-313.

34. Tsukamoto K, Machida K: Effects of life events and stress on neutrophil functions in elderly men. Immun Ageing 2012, 9(1):13.

35. El-Benna J, Dang PM, Gougerot-Pocidalo MA: Priming of the neutrophil NADPH oxidase activation: role of p47phox phosphorylation and NOX2 mobilization to the plasma membrane. Semin Immunopathol 2008, 30(3):279-289

36. El-Benna J, Dang PM, Périanin A: Peptide-based inhibitors of the phagocyte NADPH oxidase. Biochem Pharmacol 2010, 80(6):778-785.

37. Hanses F, Park S, Rich J, Lee JC: Reduced neutrophil apoptosis in diabetic mice during staphylococcal infection leads to prolonged Tnfa production and reduced neutrophil clearance. PLoS One 2011, 6(8):e23633.

38. Osborne CA, Stevens JB, Lulich JP, Ulrich JP, Bird KA, Koehler LA, Swanson $L L$ : Clinic's analysis of urinalysis. In Canine and Feline Nephrology and Urology. Baltimore: Williams \& Wilkins; 1995:136-210.

\section{Submit your next manuscript to BioMed Central and take full advantage of:}

- Convenient online submission

- Thorough peer review

- No space constraints or color figure charges

- Immediate publication on acceptance

- Inclusion in PubMed, CAS, Scopus and Google Scholar

- Research which is freely available for redistribution 